1 Long Term Durability Properties of Concrete Modified with Metakaolin and

\section{Polymer Admixture}

\author{
Adel Al Menhosh ${ }^{1,3}$, Yu Wang ${ }^{1 *}$, Yan Wang ${ }^{2}$, Levingshan Augusthus-Nelson ${ }^{1}$ \\ ${ }^{1}$ School of Computing, Science \& Engineering, University of Salford, Manchester M5 4WT, UK \\ ${ }^{2}$ School of Civil Engineering, Chongqing Jiaotong University, Chongqing 400074, China \\ ${ }^{3}$ Department of Civil Engineering, University of Basrah, Iraq
}

\title{
ABSTRACT
}

Previous studies show that both metakaolin (MK) and polymer can respectively improve certain mechanical and durability properties of concrete. Also, recent studies show that a combination of MK and polymer further enhances the mechanical properties by complement of each other. However, the knowledge of the effect on durability, a critical governing factor of concrete for the applications in extreme environments such as sewage, off-shore and bridge structures, has not been well established yet. This paper reports on a comprehensive study of the effect of metakaolin as a supplementary cementitious material together with polymer as admixture on the durability of concrete at relatively old ages. The results confirm that replacing Portland cement with $15 \%$ metakaolin and an additional $5 \%$ polymer (by weight) provide the optimum improvement for Portland cement concrete on both mechanical properties and durability.

Keywords: Metakaolin; Polymer; High Performance Concrete; Durability

*corresponding author: y.wang@salford.ac.uk 
Using mineral supplementary cementitious materials (SCM), such as fly ash (FA), silica fume (SF) and thermally activated kaolin (also known as metakaolin (MK)), as additives has already been proved effective to improve properties of concrete (Kamseu et al., 2014). MK requires less energy to produce compared to cement (Rashad, 2013; Souri et al., 2015), which, in recent years, has attracted more and more interest in the use for the SCM (Aiswarya et al., 2013; Srinivasu et al., 2014) because of the environmental concern and the decreasing supply capacity of fly ash and silica fume(Souri et al., 2015). The MK product has predominant alumina $\left(\mathrm{Al}_{2} \mathrm{O}_{3}\right)$ and silica $\left(\mathrm{SiO}_{2}\right)$ composition, which have an active pozzolanic nature (Ambroise et al., 1994). The pozzolanic reaction of MK with portlandite $\left(\mathrm{Ca}(\mathrm{OH})_{2}\right)$ will result in significant compositional changes of calcium silicate hydrate (CSH) gel to give high $\mathrm{Al}$ uptake and low $\mathrm{Ca}$ content in a new gel formation known as $\mathrm{CASH}$, which has a low $\mathrm{Ca} /(\mathrm{Al}+\mathrm{Si})$ ratio but a high $\mathrm{Al} / \mathrm{Ca}$ ratio (Souri et al., 2015).

Previous research showed that a $20 \%$ replacement of cement using MK resulted in a substantial $50 \%$ increase of the compressive strength of mortar (Khatib et al., 2012), and the concrete using MK additive displayed a lower water sorptivity compared to that using silica fume (Guneyisi et al., 2012). Recently, Pouhet and Cyr (2016) studied the pore solution carbonation of MK-based geopolymer and found that the $\mathrm{pH}$ decreased rapidly in the first few days when the normal concrete was exposed to natural $\mathrm{CO}_{2}$ conditions. Moreover, a high $\mathrm{CO}_{2}$ content or a relatively high environmental temperature led to durability issues when the $\mathrm{pH}$ was lower than 10 . However, the pozzolanic nature of $\mathrm{MK}$ increased the $\mathrm{pH}$ and kept it above 12 even after one year, indicating a minimum carbonation inside the concrete. Another study (Kannan and Ganesan, 2014) showed that self-compacting concrete (SCC) with a high MK content (up to $30 \%$ ) exhibited a significant resistance to chloride ion penetration. For acid attack resistance, the 
same SCC with 5 and 10\% of MK showed the lowest weight loss after 12 weeks immersed in 5\% $\mathrm{HCl}$ and $5 \% \mathrm{H}_{2} \mathrm{SO}_{4}$ solutions, respectively. Contrary to these advantages, it was also found, however, that the MK significantly reduces the workability of concrete and thus more water is required to improve the workability (Ambroise et al., 1994). However, the additional water to improve the workability would lead to durability issues, causing aggregate segregation, excess voids and increased porosity of the concrete.

Polymers, such as styrene-butadiene rubber (SBR) latex and polyvinyl acetate (PVA) emulsion have been commonly used as admixtures in concrete practice (Atkins et al., 1991; Konar et al., 2011). Polymer admixtures are known to not only increase the workability but also modify the physical properties of cement pastes by reducing macro voids and improving the bond strength of the polymer cement mortars to aggregates. For example, the mortar of SBR showed improvement in chloride penetration resistance along with general ionic permeability. SBR also slightly reduced portlandite content and mitigated the carbonation process (Yang et al., 2009).

The nature of the interactions between the polymers and the Portland and aluminous cements is significantly different. For Portland cement both SBR and PVA were found to retard the hydration rate to some extent, but SBR appeared to have very little chemical interaction with ordinary Portland cement (OPC) while PVA is fully hydrolysed (Atkins et al., 1991). A recent study on polymer-modified pervious concrete also found that both SBR and PVA polymers retarded the hydration reactions of cement particles and thus improved mechanical resistance and durability at prolonged curing time, for which PVA showed a better performance, but SBR showed no increase of the concrete stiffness (Giustozzi, 2016). For aluminous cement, SBR showed very little effect on the rate of hydration, but PVA was partially hydrolysed. PVA, when 
added to aluminous cements, produces a so-called macro-defect-free (MDF) matrix of superior

73 strength and fracture toughness (Atkins et al., 1991).

A literature study shows that the MK and polymer complement each other in order to improve the mechanical and durability properties. A study on Portland cement concrete using polymer, MK and FA showed a significant effect on the compressive strength, the flexural strength and the modulus of elasticity (Kou and Poon, 2013). However, it is noted that the knowledge of the durability properties of concrete modified with polymer and MK have not been well established yet (Ahmed, 2011). To meet the high-performance requirement for sewage and off-shore applications, where the durability of concrete governs the use of concrete, a series of investigations have been conducted on the combined effect of the use of MK and a polymer mixture together on the mechanical properties and durability of the modified concrete. A previous publication has reported a study of the conventional mechanical properties (Al Menhosh et al., 2016). This paper at first gives a brief review on the major findings in the previous work. After then, it reports a followed on experimental investigation on the long term durability properties of the optimum mixture identified in the previous study on mechanical properties. The durability of the optimum mix has been compared with other three benchmarks to understand the effects of the MK, polymer and their combination.

\section{MIXTURES}

\subsection{Raw Materials}

93 Portland limestone cement, CEM II/A-LL (BS EN 197-1:2011), supplied by Lafarge cement UK 94 LTD under the trade name of Mastercrete, and a premium metakaolin, produced by IMERYS 


\begin{tabular}{|c|c|c|c|}
\hline & \multicolumn{2}{|c|}{$\begin{array}{c}\text { CEM II/A-LL Cement } \\
\text { (BS EN 197-1:2011) }\end{array}$} & $\begin{array}{c}\text { Metakaolin } \\
\text { (Ambroise et al., 1994) }\end{array}$ \\
\hline Component & Values \% & Standard & Values \% \\
\hline $\mathrm{Al}_{2} \mathrm{O}_{3}$ & 4.19 & $3-5 \%$ & 40.18 \\
\hline $\mathrm{Fe}_{2} \mathrm{O}_{3}$ & 2.75 & $2.0-3.5 \%$ & 1.23 \\
\hline $\mathrm{CaO}$ & 65.00 & $60-70 \%$ & 2.0 \\
\hline $\mathrm{SO}_{3}$ & 3.19 & Less than 3.5\% & 0.0 \\
\hline $\mathrm{MgO}$ & 0.86 & $0.5-1.5 \%$ & 0.12 \\
\hline $\mathrm{Na}_{2} \mathrm{O}$ & 0.14 & Less than $0.75 \%$ & 0.08 \\
\hline $\mathrm{K}_{2} \mathrm{O}$ & 0.51 & - & 0.53 \\
\hline $\mathrm{SiO}_{2}$ & 16.19 & $15-25 \%$ & 51.52 \\
\hline $\mathrm{TiO}_{2}$ & - & - & 2.27 \\
\hline Loss on ignition (L.O.I) & - & - & 2.01 \\
\hline
\end{tabular}

group under the trade name of MetaStar 501, were used in the study. The material compositions are referenced in Table 1.

Table 1: Typical composition of cement and metakaolin

The polymer additive was styrene butadiene rubber (SBR) latex, poly vinyl acetate (PVA) emulsion and their mixtures. Normal sands were used for the fine aggregates while crushed limestone gravels were used for the coarse aggregates with a maximum size of $10 \mathrm{~mm}$. The particle size distributions of the aggregates (Menhosh et al. 2016) follow the requirements in BS 882:1992.

\subsection{Mixture Design}

Various combinations of the MK and polymers as listed in Table 2 were tested in a previous study on conventional mechanical properties (Menhosh et al. 2016). An optimum proportion was derived based on the mechanical properties of the modified concrete. To establish a baseline, a mass ratio of 1:1.5:3 for cement:sand:gravel was considered as a control mix.

Table 2: The mixtures designed (Al Menhosh et al., 2016)

\section{Concrete Mixtures}




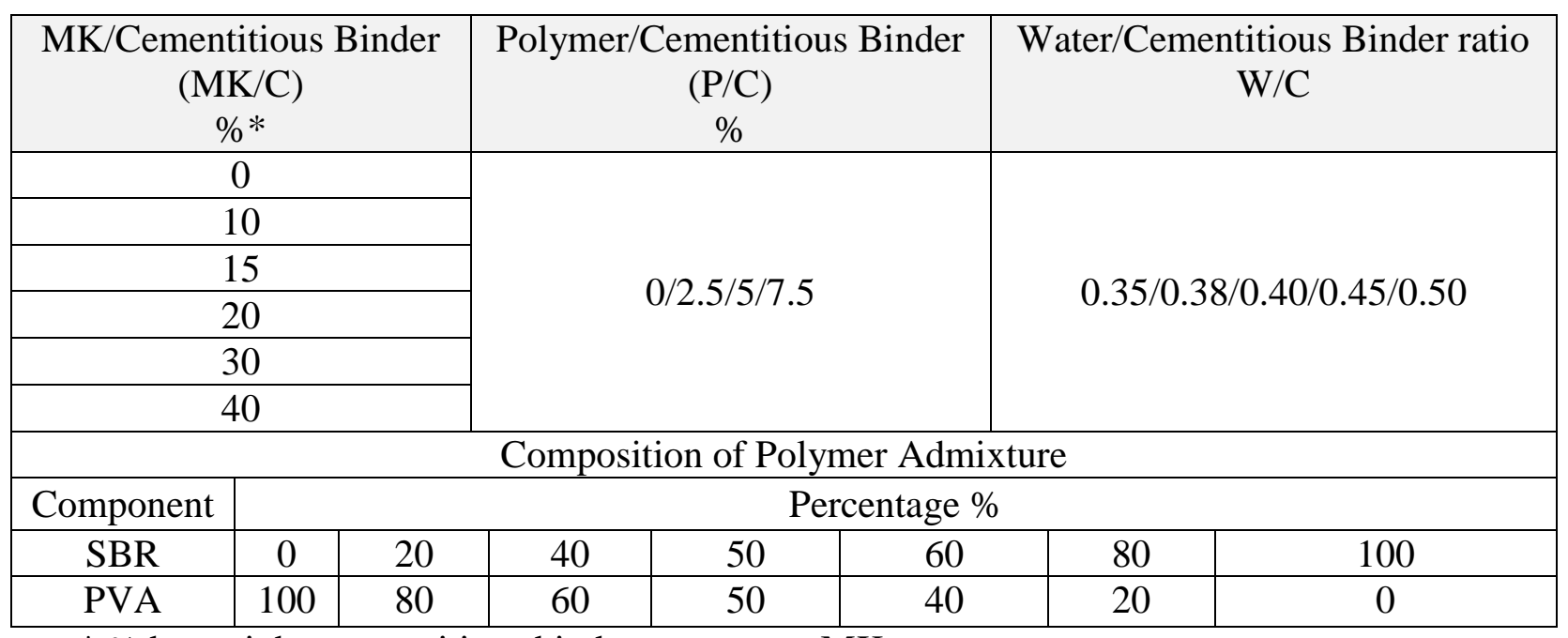

* \% by weight, cementitious binder $=$ cement $+\mathrm{MK}$

\section{CONVENTIONAL MECHANICAL PROPERTIES AND THE OPTIMUM MIX}

114 All the mixes in the Table 2 were tested for their workability and the mechanical properties at the

115 ages of 7 and 28 days. Figure 1 shows that MK significantly reduces the workability of the 116 modified mixes. The mix of $10 \% \mathrm{MK} / \mathrm{C}$ ratio has a slump value much lower than the targeted 117 range of $75 \mathrm{~mm}$ to $100 \mathrm{~mm}$ even at a high W/C ratio of 0.5 . Figure 2 shows the cubic 118 compressive strengths of the MK modified concretes at the age of 7 and 28 days for the W/C of 119 0.45. It shows that the $\mathrm{MK} / \mathrm{C}$ ratio in the range of $15 \sim 20 \%$ presents the maximum compressive strength at the two ages.

Figures 3 5 show the effect of two polymers and their mixtures on their modified concretes. It can be seen that when the polymer to cementitious binder ratio $(\mathrm{P} / \mathrm{C})$ is more than $5 \%$, the

124 strength of the modified concrete starts to deteriorate considerably. Meanwhile, when W/C ratio 125 is more than 0.45 , the deterioration on concrete strength accelerates using polymer. Figure 5

126 shows that the polymer mixture of $80 \% \mathrm{SBR}$ and $20 \% \mathrm{PVA}$ at the $5 \% \mathrm{P} / \mathrm{C}$ and $0.45 \mathrm{~W} / \mathrm{C}$ 127 presents the highest improvement on concrete strength. Figure 6 shows that the polymer mixture 
128

129

130

131 Figure 7 compares the 28 days compressive strength of mixtures using the optimum polymer

mixture at 5\% P/C and MK at 15\% MK/C separately and both together. Figure 8 shows the effect of three different curing methods on the compressive strength of the mixtures using $15 \% \mathrm{MK} / \mathrm{C}$ value is presented as the result.

Table 3: Mixtures studied in this paper

\begin{tabular}{|c|c|c|c|}
\hline Mixtures & MK/C \%* & P/C \%* & $\begin{array}{c}\text { Water to cement ratio } \\
\text { W/C }\end{array}$ \\
\hline 1 (Control) & 0 & 0 & 0.45 \\
\hline 2 & 15 & 0 & 0.45 \\
\hline 3 & 15 & 5 & 0.45 \\
\hline 4 & 0 & 5 & 0.45 \\
\hline \multicolumn{2}{|c|}{$* \%$ by the weight of cementitious binder (cement + MK) } \\
\hline
\end{tabular}
and varied $\mathrm{P} / \mathrm{C}$ ratios. All the results have suggested that using $15 \% \mathrm{MK} / \mathrm{C}, 5 \% \mathrm{P} / \mathrm{C}$ of a polymer mixture of $80 \%$ SBR and $20 \%$ PVA, $0.45 \mathrm{~W} / \mathrm{C}$ and moist curing gives the modified concrete an optimum mechanical properties.

\section{LONG-TERM PROPERTIES OF THE OPTIMUM CONCRETE}

This paper focuses on the long-term durability properties of the optimum mixture identified in section 3, and compares it with three other representative benchmark mixtures. All the four mixtures are listed in Table 3. For each data point, three samples were tested and their average

\subsection{Mechanical Properties}

\section{- Compressive Strength}

Long-term compressive strengths of concrete cubes (BS EN 12390-3: 2009) of these four mixtures up to 545 days are shown in Figure 9. It can be seen that mixtures 2 and 3 present a 
significant improvement on the control mix 1 in the long term with about $16 \%$ increase of the

150 compressive strength at the age of 545 days. The results indicate that MK has a considerable

151 effect on strength increase, but the polymer at 5\% $\mathrm{P} / \mathrm{C}$ has little influence on this property.

\section{- Splitting and Flexural Tensile Strength}

154 Figure 10 shows the splitting and flexural strengths at four ages up to 180 days. The tests were conducted according to BS EN 12390- 6:(2009) and BS EN 12390- 5:(2009), respectively. The results show that both the splitting and flexural strengths developed with age. Either using polymer $(5 \% \mathrm{P} / \mathrm{C})$ or $\mathrm{MK}(15 \% \mathrm{M} / \mathrm{C})$ increases the tensile strength. The combination of $15 \%$ $\mathrm{MK} / \mathrm{C}$ and 5\% $\mathrm{P} / \mathrm{C}$ resulted in the highest splitting and flexural strengths at almost all ages.

\section{- Young's Modulus}

161 Figure 11 shows the modulus of elasticity at the age of 28 days. The cast concrete cylinders (150 $\mathrm{mm}$ in diameter and $300 \mathrm{~mm}$ in height) were at first moist cured for 28 days according to BS

163 1881 Part -121: (1983). It can be seen that using MK has increased the Young's modulus of 164 elasticity while polymer shows the opposite effect. The mix of 5\% P/C and $15 \% \mathrm{MK} / \mathrm{C}$ shows a 165 similar result as that of 5\% P/C only. This suggests that the influence of $\mathrm{MK}$ on modulus in the 166 presence of polymer has been minimised. - Drying Shrinkage

170 Drying shrinkage is an important characteristic of concrete (Guneyisi et al., 2008), which affects

171 the long-term mechanical properties and durability properties of structures (BS ISO 1920-

172 8:2009; Hossain et al., 2016). Concrete prisms $(100 \times 100 \times 400 \mathrm{~mm})$ were cast and moist cured 
173 for 7 days. Thereafter they were stored in open atmosphere and their dimensional changes along

174 the length of the prisms were monitored and recorded up to 365 days. Figure 12 shows that both

175 MK and polymer respectively reduce the drying shrinkage. However, the optimum mix using

176 both of them shows the lowest drying shrinkage at all ages.

\section{- Rate of Water Absorption}

179 Measurement of the rate of absorption of water was made according to ASTM C1585-04. This

180 test method determines the rate of absorption of water by measuring the increase in the mass of a

181 specimen due to water absorption when only one surface of the specimen is exposed to water, as shown in Figure 13. Concrete cylinders $(100 \mathrm{~mm}$ diameter and $50 \mathrm{~mm}$ height $)$ of all the mixes were cast and moist cured for 28 days. ASTM C1585-04 recommends conducting the

184 investigation at the age of 28 days. However, reaction of MK with hydrated cement product 185 continues over time and changes the internal microstructure (Aiswarya et al., 2013; Justice et al., 186 2005). In order to understand the long-term reaction of MK and changes in the microstructure, 187 which influences the rate of water absorption, half of the specimens were dry cured for a further 18828 days. After the curing, the specimens were treated for 3 days at a temperature of 50 degrees

189 Celsius and relative humidity of $80 \%$. One circular surface was immersed in water to a depth of 1

190 to $3 \mathrm{~mm}$ only, such that water ingress of unsaturated concrete was dominated by capillary suction 191 during initial contact with water. The rate of water absorption $I$ in the unit of $\mathrm{mm}$ is defined by Eq. (1) (ASTM C1585-04):

193

194

$$
I=\frac{m_{t}}{A \times D}
$$


where $m_{t}$ is the change of weight with time $(t), A$ is the cross-sectional area of the cylinder and $D$ is the density of water. For the purpose of this test, the temperature dependence of the density of water is neglected and a value of $0.001 \mathrm{~g} / \mathrm{mm}^{3}$ is used. Figure 14 (a) and (b) show the water absorption test results for the concrete specimens cured for 28 days and the comparison of control and combined MK and polymer samples between 28 and 56 days, respectively. It can be

201 seen that the combination of MK and polymer significantly reduces the water absorption in along run, which can be attributed to a significant reduction in the capillary pores because of the pozzolanic reaction of MK with the cement hydrated products and the hydrophobic effect of polymer.

\section{- Carbonation Test}

Concrete cylinders (100 $\mathrm{mm}$ in diameter and $200 \mathrm{~mm}$ in height) were made and moist cured for 7 days. After then having the two end surfaces coated using epoxy resin, they were stored openly exposed to atmosphere. At the ages of 21, 28, 56, 90, 120 and 180 days, the cylinders were split

210 in half along the diameter to examine the depth of carbonation in the radial direction using $1 \%$

211 phenolphthalein (BS 1881-210, 2013; Papadakis, 2000; Chang and Chen, 2006). The carbonation 212 depths were measured at six different locations in the direction of the height of the specimens 213 (Otieno et al., 2014). Figure 15 shows the average values of carbonation depth. It can be seen 214 that both MK and polymer helped to decrease the carbonation rate. The optimum mixture of 5\% $215 \mathrm{P} / \mathrm{C}$ and $15 \% \mathrm{MK} / \mathrm{C}$ shows the lowest carbonation rate, at approximately half of that of the 216 control mixture at 180 days. 
219 Similar cylindrical specimens as those used for the carbonation test were prepared and moist 220 cured for 28 days. Thereafter, they were immersed in a $3 \% \mathrm{NaCl}$ solution in order to simulate a 221 chloride environment. The chloride penetration depth was monitored up to 180 days following a similar method as that used in the carbonation test. Chloride penetration depth was identified using a solution containing $0.1 \%$ sodium fluorescein and $0.1 \mathrm{~N}$ silver nitrate solution sprayed on the two surfaces exposed by splitting through the specimens along the diameter (Andrade at al., 1999; Meck and Sirivivatnanon, 2003). The penetration depth was measured in the same way as that for carbonation. Figure 16 shows a similar trend as that of the carbonation test. Both polymer and MK decreased the chloride penetration rate considerably. The optimum mixture of 5\% $\mathrm{P} / \mathrm{C}$ and $15 \% \mathrm{MK} / \mathrm{C}$ demonstrated the best resistance to chloride penetration.

\section{- Corrosion Weight Loss}

231 Reinforced concrete cubes $(100 \times 100 \times 100 \mathrm{~mm})$ were cast with a $60 \mathrm{~mm}$ long carbon steel rebar 232 of diameter $16 \mathrm{~mm}$ positioned in each cube and parallel to a surface at a depth of $25 \mathrm{~mm}$ from 233 that surface. Before casting, the carbon steel rebar was thoroughly cleaned and weighed to 234 confirm its initial weight as that described by Parande et al. (2008). These cast reinforced 235 specimens were moist cured for 28 days (Parande et al., 2008). To simulate the real world 236 situation where concrete is subjected to various service conditions from normal atmosphere to 237 submerged under saline environments over time, the samples were divided into three groups and 238 each group was exposed to different conditions. One group was exposed to an open atmospheric 239 environment, another group was immersed in a $20 \% \mathrm{NaCl}$ solution, and the last group was 240 alternately put in these two environmental conditions for 7 days each and up to 38 cycles in 365 241 days. On the time after 180, 270 and 365 days, the concrete specimens were split open using 242 compressive machine and subjected to visual observation at first. Thereafter the steel 
243 reinforcements were pulled out from the concrete and their surfaces were carefully cleaned

244 thoroughly using steel wire brush to get rid of all the concrete remains and the rusts of corrosion.

245 Later the cleaned steel rebars were weighed again to work out their weight loss due to corrosion

246 (Chung, 2000; Parande et al., 2008). Figure 17 shows that the weight losses of all samples under

247 all three conditions are obvious, particularly, for the samples of the control mix of $0 \% \mathrm{P} / \mathrm{C}$ and

$248 \mathrm{MK} / \mathrm{C}$. However, the samples of the optimum mix of 5\% $\mathrm{P} / \mathrm{C}$ and 15\% MK/C has the lowest 249 weight loss. It can be also noticed that the weight loss became significant after 270 days. 250 Particularly, the alternated exposure to atmospheric condition and immersion in $20 \% \mathrm{NaCl}$ 251 demonstrates a critical influence. It can be concluded that an alternating environmental condition 252 accelerate the corrosion rate in concrete.

\section{- Chemical Resistance}

255 The chemical resistance was inspected by immersing cubic specimens $(100 \times 100 \times 100 \mathrm{~mm})$, after 25628 days moist curing, in four different chemical solutions for 180 days. These solutions were $25720 \%$ sodium hydroxide $(\mathrm{NaOH}), 5 \%$ sodium chloride $(\mathrm{NaCl}), 5 \%$ sulphuric acid $\left(\mathrm{H}_{2} \mathrm{SO}_{4}\right)$ and $5 \%$ 258 hydrochloric acid $(\mathrm{HCl})$. They were selected to simulate various environmental conditions 259 (Beulah and Prahallada, 2012). In practice, special cements (for example sulphur resistance 260 cement), which are very expensive, have been used for the application in severe environments. 261 This experimental investigation aims to help understand how effective using ordinary MK and 262 polymer modified Portland cement to replace the special cements to meet these special 263 requirements.

265 Figure 18 shows the appearance of the samples modified with 5\% P/C and 15\% MK/C after 90 266 days exposed to $\mathrm{HCl}$ and $\mathrm{H}_{2} \mathrm{SO}_{4}$, and all the samples after 180 days immersed in the acidic 
solutions. The weight changes of the specimens were recorded at 7, 14, 28, 56, 90 and 180 days.

268 Figure 19 show that the mixtures using either MK or polymer had less weight increase when exposed to the alkaline and salty solutions, and less weight loss when exposed to acidic solutions, compared to the control mix with no modification using MK and polymer. It can be noticed, however, that when exposed to alkaline and salty solutions all mixtures had a steep weight increase in the first 56 days, which indicates that the cured concrete underwent further chemical reactions with infiltrated salt and alkali ions in an early stage. The MK modified mixtures have a significantly reduced weight change in all the tests. It effectively confirms the pozzolanic reactions between MK and cement hydration products, which result more hydration gel products with a formation of CASH and NASH (Kannan and Ganesan, 2014) to help the resistance to chemical attack. The optimum mixture of 5\% $\mathrm{P} / \mathrm{C}$ and $15 \% \mathrm{MK} / \mathrm{C}$ presents the least weight change in all the cases. It also can be seen that all these curves present a flatting trend after 90 days, indicating a long-term durability, in which the optimum mixture shows the best.

\section{- Water Flow Rate of Concrete}

282 In this study, both mortar and concrete specimens, of the dimension of $2.54 \mathrm{~cm}$ in diameter and $2832.54 \mathrm{~cm}$ in length, were tested. The specimens were moist cured for 28 days and tested at ages 284 28, 56 and 90 days. The PERL-200 permeameter, provided by Core Lab Instruments, was used 285 for the test. Similar to the test apparatus used by Kameche et al. (2014) and Li et al. (2016), 286 incorporating a digital pressure transducer and a calibrated visual flow (measurement) cell, it 287 uses the valves to control a flow system to enable the determination of flow rate of water through 288 a one-inch diameter core sample plug. The water flow rate through the sample is determined by 289 measuring the time required for the water $\left(10 \mathrm{~cm}^{3}\right)$ to pass between the calibrations marks. 290 Figure 20 shows the schematic diagram of the experimental setup. The permeability of the 
sample can be determined in terms of the Darcy's Law:

$$
Q=\frac{k \times A\left(P_{1}-P_{2}\right)}{\mu \times L}
$$

where, $Q$ is flow rate $(\mathrm{cc} / \mathrm{sec}), k$ is the permeability, $L$ is the length of flow $(\mathrm{cm}), \mu$ is the viscosity, $A$ is the cross-sectional area of flow $\left(\mathrm{cm}^{2}\right), P_{1}$ is the upstream pressure, and $P_{2}$ is the downstream pressure. All the concrete and mortar samples were tested using this apparatus.

Figures 21 (a) and (b) illustrate the results obtained from concrete and mortar, respectively. Clear evidence can be seen that the water flow rate significantly reduced for concrete modified by MK and polymer. The mortar sample of the optimum mix of $5 \% \mathrm{P} / \mathrm{C}$ and $15 \% \mathrm{MK} / \mathrm{C}$ shows the lowest the permeability.

\section{- Depth of Penetration of Water under Pressure}

304 The water penetration test (BS EN-12390-8, 2009), the most commonly used test to evaluate the permeability of concrete, was conducted as well. In this test, water was applied on one face of the $150 \times 150 \times 150 \mathrm{~mm}$ concrete cube specimens under a pressure of $0.5 \mathrm{MPa}(5 \mathrm{bars})$, as shown in

Figure 22. This pressure was maintained constant for a period of $72 \mathrm{hrs}$. After the completion of

308 the test, the specimens were taken out and split open into two halves. The water penetration front

309 profile in concrete was then marked (Figure 23(a)) and the maximum depth of water penetration 310 front in specimens was recorded and considered as an indicator of the water penetration (Dinakar 311 et al., 2013). This test was conducted at 28, 56 and 90 days after moist curing for 28 days. As can 312 be seen in Figures 23(b), the depth of penetration of water significantly reduced in the specimen 313 of the optimum mix of $4 \% \mathrm{P} / \mathrm{C}$ and $15 \% \mathrm{MK} / \mathrm{C}$ compared with the rest of the samples. 314 Furthermore, there is a development in water permeability of the modified concrete with 
315 increased age of the specimens compared with the control sample. This can be attributed to the 316 continuous reaction of MK with the hydrated cement product, producing a less permeable matrix 317 with time.

\section{- Gas Penetration of Concrete under Pressure}

320 In this test, the similar experimental setup and samples were used as in the test for depth of 321 penetration of water under pressure. However, the $\mathrm{CO}_{2}$ was applied from the top instead from the 322 bottom with a pressure of $0.4 \mathrm{MPa}$ (4 bars) for 8 hours. These arrangements were implemented to 323 maintain the constant pressure in order to simulate the concrete under sewerage conditions. After 324 the test, the specimens were taken out and split open into two halves. The penetration of 325 carbonation was determined by treating a freshly broken surface with $1 \%$ phenolphthalein. The 326 region of $\mathrm{Ca}(\mathrm{OH})_{2}$ is coloured pink while the carbonated areas is uncoloured. The gas penetration 327 profile on the concrete surface was then marked and the maximum depth of gas penetration in 328 specimens was recorded and considered as an indicator of the gas penetration. Figure 24 329 compares the gas penetration depths of the four mixtures. It can be seen that using MK and 330 polymer respectively have exhibited reductions in the gas penetration. The optimum mix of 5\% $331 \mathrm{P} / \mathrm{C}$ and $15 \% \mathrm{MK} / \mathrm{C}$ shows the best result for the gas penetration resistance.

\section{CONCLUSIONS}

334 This paper has reported an experimental study on long-term durability properties of concrete 335 modified with $\mathrm{MK}$ and polymer. Various long-term durability tests were carried out to 336 understand the behaviour of modified concrete subjected to an extremely harsh environment. The 337 following conclusions can be drawn based on the experimental results: 
- Metakaolin will accelerate the setting time of cement pastes but reduce the workability of concrete. However, polymer has an inverse influence on the two properties.

- The bi-polymer of composition $80 \%$ SBR and 20\% PVA shows an optimised result when it $341 \quad$ works together with MK.

- The addition of 5\% optimised bi-polymer and $15 \%$ cement replacement by metakaolin generates an optimised concrete mixture for long-term mechanical properties.

- All the long-term durability experimental investigations suggest that both MK and polymer improve the properties. Their combination presents a complement to each other. The optimum mix base on mechanical properties also demonstrates a great enhance on durability properties

\section{Acknowledgments}

This work was funded by the Iraqi Ministry of Higher Education and Scientific Research

Scholarship Program.

\section{References}

Ahmed, S. F. U. (2011). Mechanical and durability properties of mortars modified with combined polymer and supplementary cementitious materials. Journal of Materials in Civil Engineering, 23(9), 1311-1319.

Aiswarya, S., Prince Arulraj, G., and Dilip, C. (2013). A review on use of metakaolin in concrete. IRACST - Engineering Science and Technology.

Al Menhosh, A., Wang, Y., and Wang, Y. (2016). The mechanical properties of the concrete using metakaolin additive and polymer admixture. Journal of Engineering, 2016, 1-6.

Ambroise, J., Maximilien, S., and Pera, J. (1994). Properties of metakaolin blended cements. Advanced Cement Based Materials, 1(4), 161-168.

Andrade, C., Castellote, M., Alonso, C., and González, C. (1999). Relation between colourimetric chloride penetration depth and charge passed in migration tests of the type of standard ASTM C1202-91. Cement and Concrete Research, 29(3), 417-421. 
Atkins, K. M., Edmonds, R. N., and Majumdar, A. J. (1991). The hydration of portland and aluminous cements with added polymer dispersions. JOURNAL OF MATERIALS SCIENCE, 26, 2372-2378.

ASTM Standards C1585 - 04(2004). Measurement of Rate of Absorption of Water by Hydraulic Cement Concrete, U. S.

Beulah, M. A., and Prahallada, M. C. (2012). Effect of replacement of cement by metakalion on the properties of high performance concrete subjected to hydrochloric acid attack. International Journal of Engineering Research and Applications, 2.

BS EN 12390-3: (2009) : Testing hardened concrete: Compressive strength of test specimens. BSI: London

BS EN 12390-5: (2009): Testing hardened concrete: Flexural strength of test specimens, BSI: London

BS EN 12390- 6:(2009):Testing hardened concrete: Tensile splitting strength of test specimens, BSI: London

BS EN 12390 - 8: (2009) : Depth of penetration of water under pressure. BSI: London

BS EN 197-1: (2011): Cement: composition, specifications and conformity criteria for common cements. British Standards Institution, London.

BS ISO 1920-8:2009: Testing of concrete. Determination of the drying shrinkage of concrete for samples prepared in the field or in the laboratory, BSI: London

BS 1881 Part -121: (1983): Method for determination of static modulus of elasticity in compression, BSI: London

BS 1881 -210 : (2013) : Determination of the potential carbonation resistance ofconcrete Accelerated carbonation method. . BSI: London

BS 882: (1992): Specification for aggregates from natural sources for concrete, BSI: London

Chang, C. F., and Chen, J. W. (2006). The experimental investigation of concrete carbonation depth. Cement and Concrete Research, 36(9), 1760-1767. doi: 10.1016/j.cemconres.2004.07.025

Chung, D. (2000). Corrosion control of steel-reinforced concrete. Journal of Materials Engineering and Performance, 9(5), 585-588.

Dinakar, P., Sahoo, P. K., and Sriram, G. (2013). Effect of Metakaolin Content on the Properties of High Strength Concrete. International Journal of Concrete Structures and Materials, 7(3), 215-223. doi: 10.1007/s40069-013-0045-0 
Giustozzi, F. (2016). Polymer-modified pervious concrete for durable and sustainable transportation infrastructures. Construction and Building Materials, 111, 502-512. doi: 10.1016/j.conbuildmat.2016.02.136

Guneyisi, E., Gesoglu, M., Karaoglu, S., and Mermerdas, K. (2012). Strength, permeability and shrinkage cracking of silica fume and metakaolin concretes. Construction and Building Materials, 34, 120-130.

Guneyisi, E., Gesoğlu, M., and Mermerdaş, K. (2008). Improving strength, drying shrinkage, and pore structure of concrete using metakaolin. Materials and Structures, 41(5), 937949.

Hossain, M. M., Karim, M. R., Hasan, M., Hossain, M. K., and Zain, M. F. M. (2016). Durability of mortar and concrete made up of pozzolans as a partial replacement of cement: A review. Construction and Building Materials, 116, 128-140. doi: 10.1016/j.conbuildmat.2016.04.147

Justice, J. M., Kennison, L. H., Mohr, B. J., Beckwith, S. L., McCormick, L. E., Wiggins, B., Zhang, Z. Z., and Kurtis, K. E. (2005). Comparison of Two Metakaolins and a Silica Fume Used as Supplementary Cementitious Materials. Paper presented at the Proc. Seventh international symposium on utilization of high-strength/high performance concrete, Washington D.C.

Kamseu, E., Cannio, M., Obonyo, E. A., Tobias, F., Bignozzi, M. C., Sglavo, V. M., and Leonelli, C. (2014). Metakaolin-based inorganic polymer composite: Effects of fine aggregate composition and structure on porosity evolution, microstructure and mechanical properties. Cement and Concrete Composites, 53, 258-269.

Kameche, Z. A., Ghomari, F., Choinska, M., and Khelidj, A. (2014). Assessment of liquid water and gas permeabilities of partially saturated ordinary concrete. Construction and Building Materials, 65, 551-565. doi: 10.1016/j.conbuildmat.2014.04.137

Kannan, V., and Ganesan, K. (2014). Chloride and chemical resistance of self compacting concrete containing rice husk ash and metakaolin. Construction and Building Materials, 51, 225-234. doi: 10.1016/j.conbuildmat.2013.10.050

Khatib, J. M., Negim, E. M., and Gjonbalaj, E. (2012). High Volume Metakaolin as Cement Replacement in Mortar. World journal of chemistry, 7(1), 7-10. doi: 10.5829/idosi.wjc.2012.7.1.251

Konar, B. B., Das, A., Gupta, P. K., and Saha, M. (2011). Physicochemical Characteristics of Styrene-Butadiene Latex- modified Mortar Composite vis-à-vis Preferential Interactions. Journal of Macromolecular Science, Part A, 48(9), 757-765. doi: $10.1080 / 10601325.2011 .596072$

Kou, S. C., and Poon, C. S. (2013). A novel polymer concrete made with recycled glass aggregates, fly ash and metakaolin. Construction and Building Materials(41), 146-151. 
Li, X., Xu, Q., and Chen, S. (2016). An experimental and numerical study on water permeability of concrete. Construction and Building Materials, 105, 503-510. doi: 10.1016/j.conbuildmat.2015.12.184

Meck, E., and Sirivivatnanon, V. (2003). Field indicator of chloride penetration depth. Cement and Concrete Research, 33(8), 1113-1117.

Nguyen, D. D., Devlin, L. P., Koshy, P., and Sorrell, C. C. (2016). Effects of chemical nature of polyvinyl alcohol on early hydration of Portland cement. Journal of Thermal Analysis and Calorimetry, 123(2), 1439-1450. doi: 10.1007/s10973-015-5076-0

Otieno, M., Beushausen, H., and Alexander, M. (2014). Effect of chemical composition of slag on chloride penetration resistance of concrete. Cement and Concrete Composites, 46, 5664. doi: 10.1016/j.cemconcomp.2013.11.003

Papadakis, V. G. (2000). Effect of supplementary cementing materials on concrete resistance against carbonation and chloride ingress. cement and concrete research, 30, 291-299.

Parande, A., Babu, B., Karthik, M., Kumaar, K., and Palaniswamy, N. (2008). Study on strength and corrosion performance for steel embedded in metakaolin blended concrete/mortar. Construction and Building Materials, 22(3), 127-134. doi: 10.1016/j.conbuildmat.2006.10.003

Pouhet, R., and Cyr, M. (2016). Carbonation in the pore solution of metakaolin-based geopolymer. Cement and Concrete Research(88), 227-235.

Rashad, A. M. (2013). Metakaolin as cementitious material: History, scours, production and composition-A comprehensive overview. . Construction and building materials, 41, 303318.

Souri, A., Kazemi-Kamyab, H., Snellings, R., Naghizadeh, R., Golestani-Fard, F., and Scrivener, K. (2015). Pozzolanic activity of mechanochemically and thermally activated kaolins in cement. Cement and Concrete Research(77), 47-59.

Srinivasu, K., Krishna Sai, M. L. N., and Venkata Sairam Kumar, N. (2014). A review on use of metakaolin in cement mortar and concrete. Paper presented at the International journal of innovative research in science, engineering and technology.

Wang, R., Li, X.-G., and Wang, P.-M. (2006). Influence of polymer on cement hydration in SBR-modified cement pastes. Cement and Concrete Research, 36(9), 1744-1751. doi: 10.1016/j.cemconres.2006.05.020

Yang, Z., Shi, X., Creighton, A. T., and Peterson, M. M. (2009). Effect of styrene-butadiene rubber latex on the chloride permeability and microstructure of Portland cement mortar. Construction and Building Materials, 23(6), 2283-2290. doi: 10.1016/j.conbuildmat.2008.11.011 